\title{
ERRATUM
}

Attila Nemes • Remco G.M. Timmermans

J.H. Paul Wilson • Osama I.I. Soliman

Boudewijn J. Krenning • Folkert J. ten Cate

Marcel L. Geleijnse

\section{The mild form of mucopolysaccharidosis type I (Scheie syndrome) is associated with increased ascending aortic stiffness}

Heart Vessels (2008) 23:108-111

In the Abstract, there was an error in the 8th line from the end. The parenthetical expression should read: $(1.6 \pm 0.8 \mathrm{vs}$ $4.6 \pm 1.9 \mathrm{~cm}^{2} /$ dynes $\left.10^{-6}, P<0.001\right)$

A. Nemes · O.I.I. Soliman · B.J. Krenning · F.J. ten Cate $(\triangle)$

M.L. Geleijnse

Department of Cardiology, Thoraxcenter, Erasmus Medical Center

Rotterdam, Dr Molewaterplein 40, Room Ba304, 3015 GD

Rotterdam, The Netherlands

Tel. +31-10-463-5669; Fax +31-10-463-5498

e-mail: f.j.tencate@erasmusmc.nl

R.G.M. Timmermans · J.H.P. Wilson

Department of Internal Medicine, Erasmus MC, Rotterdam, The Netherlands

A. Nemes

2nd Department of Medicine and Cardiology Center, University of Szeged, Szeged, Hungary

O.I.I. Soliman

Department of Cardiology, Al-Hussein University Hospital,

Al-Azhar University, Cairo, Egypt 